\title{
Designing a Curriculum for a Distance Learning Class: An Example of a First-year Japanese Course
}

\author{
Noriko Fujioka-Ito \\ McMicken College of Arts \& Sciences, University of Cincinnati, Japanese Program, Cincinnati, Ohio, USA
}

\begin{abstract}
Although technology has been integrated widely in foreign language courses and has shown positive results for foreign language learners, it is challenging to teach critical languages that do not have commercially developed, online-based textbook packages for distance learning courses. The distance separating students sometimes hinders the provision of learning experiences focused on social and cultural contexts in distance learning courses. This article discusses how online learning communities play important roles as networks of social relationships in which engagement and interaction are critical to the distance-learning courses. In online learning communities, the instructor's scaffolding through the step-by-step process as well as collaboration with peers further helps enhance students' success. In the course discussed in this article, students enrolled in a first-year Japanese distance-learning course developed basic communicative skills and increased their awareness of cultural differences through the instructor's intervention and collaborative work with peers by using a combination of synchronous and asynchronous components of the course management system. The results of a nine-month investigation report students' attitudes toward distance learning classes based on their feedback from a course survey.
\end{abstract}

Index Terms - curriculum development, distance-learning, intercultural competence, learner autonomy, online learning community

\section{INTRODUCTION}

Technology has impacted educational environments significantly and continues to do so although potential disadvantages or limitations of online learning have been identified. Research has indicated drawbacks to online learning, including learner isolation (Brown, 1996); learner frustration, anxiety, confusion (Hara \& Kling, 2000); and the need for more discipline, self-motivation, and time commitment to learning (Golladay, Prybutok, \& Huff, 2000; Serwatka, 2003). The U.S. Department of Education (2009) reported that online learning offered an advantage over traditional classroom instruction. According to the findings of analysis conducted by the U.S. Department of Education, students who took all or part of their classes online performed better than those in traditional face-to-face instruction. Furthermore, students in blended (or hybrid) classes performed better than those in purely online courses. The investigator concluded that instruction using technology is more effective compared to purely traditional face-to-face instruction because increased time on task and learner reflection in online learning environments through interactions with media help students reach higher levels of achievement.

Nevertheless, effectively giving instructions related to critical languages (less commonly taught languages such as Japanese and Arabic) that do not have commercially developed, online-based textbook packages, including class schedules, materials, and assessment, is challenging in distance learning courses aimed at providing quality instruction equal to that of face-to-face classes. Currently, only a few instructors in the field of Japanese language education have developed curricula for teaching distance learning courses in the United States; therefore, one of the aims of this article is to show an example of the distance learning course developmental processes.

This article focuses on methods to bridge the distance separating student from student as well as student from instructor to enhance the success of a diverse group of students in a virtual classroom. The first part discusses how a first-year Japanese distance learning course was planned. The second part describes how the distance learning course was managed to develop basic communicative skills and global views simultaneously using the synchronous and asynchronous online components of Blackboard. Finally, distance learning students' feedback from a course survey is reported.

\section{THEORETICAL BACKGROUND}

\section{A. Online Learning Community}

Both individual and social learning processes affect learning outcomes. According to Jonassen, Peck, and Wilson (1999), the five attributes of meaningful learning are "active, constructive, intentional, authentic, and cooperative" (p. 7). In particular, cognitive constructivism claims that individual construction of knowledge is discovered through 
interaction in the environment (Bonk \& Cunningham, 1998). From a social constructivist perspective, "Meaning making is a process of negotiation among the participants through dialogue or conversations" (Jonassen et al., 1999, p. 5). Thus, from the constructivist's viewpoint, online learning communities in distance learning classes play important roles as networks of social relationships in which engagement and interaction are critical to the learning environment.

In practice, online learning communities not only reduce the potential for learner isolation, but also provide learners with social dimensions that enhance instructional effectiveness, increase dynamic interaction, encourage learning satisfaction, foster in-depth discussion, and facilitate collaborative learning (Lomicka \& Lord, 2007). Technology can be a tool for exploring, representing, and articulating knowledge as well as a medium for conversing and collaborating. Using these advantages, online learning communities in which individualized attention by the instructor and collaboration among peers occur can enhance student success through a cyclical relationship using online components that emphasize social formation.

Online classes can be conducted using a combination of synchronous and asynchronous components. Both components offer advantages and disadvantages. Synchronous e-learning (e.g., teleconference, webcast, web conference) provide learners with live, depersonalized, concurrent, and collaborative learning opportunities similar to classroom settings; however, synchronous e-learning is normally scheduled, whereas asynchronous e-learning (e.g., email, discussion forum, podcasting, interactive multimedia content) is self-paced and available at any time. The flexibility of learning environments in asynchronous e-learning enables learners to increase time on task and learner reflection utilizing media.

Although computer-mediated communication (CMC) initially was not considered a personal communicative device (Baron, 1984; Kiesler, Siegel, \& McGuire, 1984) due to its lack of paralinguistic elements, CMC is no longer viewed as "socially impaired" (Baym, 1995) from media-deterministic perspectives. Indeed, the results of many studies support the idea that CMC can create a socially rich environment (e.g., Michinov, Michinov, \& Toczek-Capelle, 2004). CMC using asynchronous e-learning tools, such as discussion forums, is effective in building a socially rich environment for online learning communities. Asynchronous e-learning tools can bridge the distance separating student from student as well as student from instructor through interaction and as intermittently collaborative learning. These also can be useful devices for building group activities and teamwork, thereby providing opportunities that enable learners to understand by communicating with others.

However, based on the results from a questionnaire used to investigate the usability of online social networks for foreign-language learning purposes, Stevenson and Liu (2010) reported that $47 \%$ of users indicated that the "Discussion Board" section of their online class site was not helpful in meeting their goals as language learners. These results further demonstrate the concern expressed by some users regarding the social aspect of the website being inappropriate for the learning elements of the site. Others expressed frustration with the limited capabilities of the site to promote collaboration with and learning from other users. Therefore, well-planned curricula are necessary to make the Discussion Board more effective, so learners are provided opportunities to interact with classmates and exchange information, knowledge, and thoughts.

\section{B. Development of Intercultural Abilities}

Using online components that emphasize social formation, thereby enhancing global views and cross-cultural understanding, is necessary for distance learning students who are learning foreign languages as culture has been emphasized as the core of the foreign language curriculum in such publications as Standards for Foreign Language Learning in the $21^{\text {st }}$ Century (National Standards in Foreign Language Education Project, 1999). According to Byram's (2000) definition (Byram, 1997; Byram \& Zarate, 1997), intercultural competence (ICC) refers to the ability to perceive relationships between different cultures both internally and externally. "Intercultural" reflects the view that foreignlanguage students must gain insight into their native culture as well as the target culture to mediate and explain differences. In addition, these students need to become aware of the meeting of cultures that occurs in communication using the learned foreign language (Kramsch, 1993). Interculturally competent people should be able to mediate either for themselves or for other people by interpreting each in terms of the other. They can critically or analytically understand their own and other cultures through conscious processes based on their own perspectives.

In effectively developing ICC in distance learning courses, e-forum entries are useful tools that allow learners to exchange views with speakers of the target language. Some studies investigated the effectiveness of an online learning environment developed to foster the ICC of foreign language learners using an e-forum. For example, Liaw (2006) reported research results regarding data categorized and analyzed using four types of ICC that emerged in students' eforum entries based on Byram's (1997) model, which proposed a general curriculum development process for ICC. The four types of ICC in Liaw's study are (a) interest in knowing other people's way of life and introducing one's own culture to others, (b) ability to change perspective, (c) knowledge about one's own culture and others' culture for ICC, and (d) knowledge about ICC processes. The findings of Liaw's study, based on qualitative data analysis, were: (a) Most entries fell under the category of "knowledge about one's own and others' culture for ICC." (b) The second largest category was an "interest in knowing other people's way of life and introducing one's own culture to others." (c) The smallest category was the "ability to change perspective." These results indicated that the students in Liaw's study tended not only to gain knowledge of the target culture, but also discovered and reflected when their understanding of the behaviors, beliefs, concepts, and methods of interacting in the native and target cultures was exchanged with other 
students. These findings could be evidence that the students realized and learned important facts about the target culture. Additionally, they could successfully communicate with people of the target language about both target and native cultures and maintain communication for a long period of time.

\section{REDESIGN OF COURSE CURRICULUM}

Despite the fact that some remarkable software (e.g., Natural Language Processing techniques_-parsing) can analyze whether students' answers are correct and can provide flexible feedback based on students' input, this capability tends to be limited to the sentence level. For students enrolled in the present distance learning course to further develop language skills beyond the sentence level, the curriculum of the distance learning course discussed in this article was developed carefully. This section describes how the syllabus of this distance learning course was developed using the same textbook, An Integrated Course in Elementary Japanese: Genki I, (Banno, Ohno, Sakane, \& Shinagawa, 1999) and workbook as an in-class course but incorporating the considerations of how distance between the students and their instructor was bridged effectively to foster autonomous learning abilities.

\section{A. Course Redesign}

Learning autonomy is one of the key elements to success in distance learning and self-instruction. Autonomous learners transcend the barriers between learning and living, according to the definition of autonomous learning in the fields of educational psychology, educational theory, and curriculum development (e.g., Barners, 1976; Bruner, 1966; Illich, 1979; Rogers, 1983); namely, autonomous learners tend to integrate what they learn in the formal context of the classroom with what they already know through experiences in real-life situations (Little, 1995).

This distance learning course was designed based on the curricula of face-to-face courses with consideration for promoting autonomy because White (1995) discussed that distance learners who develop more metacognitive strategies and autonomous learning abilities learn in a similar manner as classroom learners. The year-long goal was determined referring to Novice-High proficiency level guidelines of the Oral Proficiency Interview of the American Council on the Teaching of Foreign Languages (American Council on the Teaching of Foreign Languages, 1999) ${ }^{1}$. To achieve this goal at the end of the year, students should succeed in managing uncomplicated communicative tasks in straightforward social situations using cultural understanding and the skills to find information relating to these abilities as acquired in the course. The processes of course design were mainly (a) to set course goals, sub-goals, and activities in the graphic organizations of the syllabi; (b) to consider effective methods of developing ICC as well as basic communicative skills using synchronous and asynchronous components of Blackboard (the course management system) for distance learning courses; and (c) to develop assessment devices (such as tailored course evaluations).

\section{Graphic organizations in syllabi}

Concept maps in syllabi include cross-links that describe the relationships among the objectives and sub-objectives of activities and assessments. These graphical tools enhance organizing and representing knowledge, so students of a distance learning course who have little knowledge about a discipline can acquire a valid hierarchical schema for organizing disciplinary knowledge (Nilson, 2007) and more easily identify how the activities and assessment are associated. These kinds of maps effectively can present the objectives and the content of the course to the students, visually showing how elements such as the ability to write characters, use grammar, and search resources all reinforce one another. Since young people have been raised with television, video games, and the Internet, students better learn visually how all aspects of the language are associated and which activities help develop each language skill in distance learning environments. Although a syllabus was developed for each term ${ }^{2}$, Figure 1 shows an example of graphic organizations in the first-term syllabus.

Figure 1 is a map that puts the year-long goal at the top while the objectives of the course are included in the big blue circle. Sub-objectives guide the actual skills being assessed in the colored circles on the outside. The goal of this course is for students to master basic communicative abilities in the Japanese language. In addition, they should develop a cultural understanding and the skills to find information relating to these abilities.

\section{Promising syllabus}

Promising syllabi make assurances rather than demands, providing students with intellectual, personal, and artistic options, including statements to encourage the students' motivation to study to foster deeper and more enthusiastic learning. Whereas a regular syllabus provides the goals and the objectives of the course determined by the curriculum designers or instructors and the standard information regarding course logistics, the promising syllabus provides students with opportunities to freely consider their learning plans and imagine their future based on the "promises" written from the students' viewpoints. Bain's (n.d.) model includes three elements in a promising syllabus. The first element consists of "The Promises," delivered in a story format, which tells the students how the course will help them. The first part of a promising syllabus enables students to understand what skills will be developed through learning processes of the course and what students will be able to do after graduating. The second element consists of the "Ways to Fulfill Those Promises," where the content of the course is described using student-centered language. The second part of a promising syllabus is similar to what is known as requirements and assignments in a regular syllabus; however, it avoids using "requirements" and "assignments;" instead, students' responsibilities and ways to enhance students' 
learning are described. The last element describes how students can self-evaluate their own learning and thinking progress.

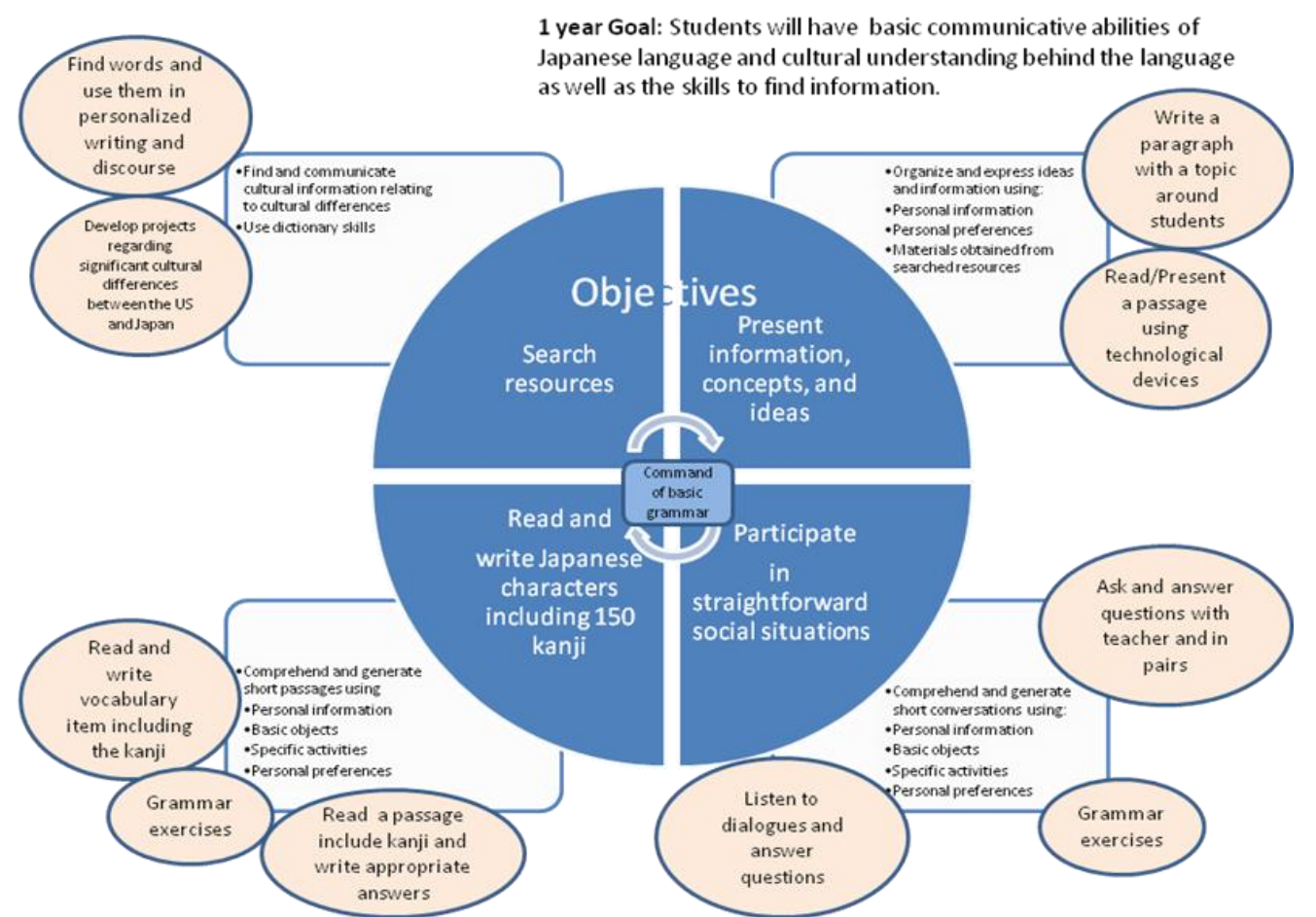

Figure 1. Example of graphic organizations, including a one-year goal, objectives, sub-objectives, activities, and assessment.

The last part of the syllabus for the present distance learning course contains "Promising Syllabus Paragraphs" that emphasize the importance of communication with people who speak the target language. It also stresses how study abroad could promise to bring success in foreign language learning to students (see Appendix 1). Because distance learning students have fewer opportunities to practice their language learning in face-to-face settings, participation in study abroad programs is encouraged, so students are exposed to target languages and cultures and can practice communication in real-life situations. In addition, the last part of the syllabus includes the instructor's biography, so students can get to know and feel closer to their instructor even though they do not meet every day. These items are in different fonts to clearly separate them from the sections explaining course logistics. It is hoped that this stylistically unique part of the syllabus helps students become more dedicated to learning a language and its culture, using such knowledge in real-life settings, and continuing to expand such knowledge throughout life.

\section{Development of activities/projects and assessment tools}

As previously mentioned, distance learning students better understand the course goals and content if graphic organizations that visually show the associations of objectives, sub-objectives, activities/projects, and assessment are included in the syllabus. The one-year goal of this distance learning course is for students to obtain basic communicative skills and understand the target culture as well as to develop the ability to find information relating to these skills (see Figure 1). Hence, activities/projects that enable students to practice basic communicative skills and simultaneously enhance ICC were designed to provide students in a distance learning course practice with meaningful tasks. These activities/projects are helpful because students in distance learning courses need to work without physically meeting their instructors, who are from countries where the target languages are spoken or who are very familiar with target cultures.

To elicit students' feedback about the entire course, the course survey, consisting of parts of the standardized course evaluation developed by the language departments and a tailored form course evaluation created by the course instructor, was conducted at the end of each term. Tailored form course evaluations are constructed for a specific course curriculum to gather not only the learners' opinions with regard to course materials, activities, and learning strategies, but also their concerns about future courses whereas a traditional course evaluation is a means to produce feedback that can be useful in improving both the instructors' quality of instruction and the structure of the course. Thus, tailored form course evaluations are better methods for receiving feedback from students with whom the instructor usually does not meet daily or alternate-day face-to-face settings. In addition to the six questions from the standardized course evaluation (instructor's grading fairness, attention to the students' progress, encouraging use of a target language, the most beneficial aspects of the course, suggestions to improve the course, and additional comments), the students were asked to evaluate how frequently they used course resources, how much they feel they have learned from the course materials and class activities, the benefits about the way in which the distance learning course was taught, effective 
learning strategies they used and would like to share with their classmates, and the most memorable moment in the course (see Appendix 2).

\section{B. Developing an Online Learning Community}

This section describes how synchronous and asynchronous online components are utilized to develop learners' basic communicative skills and ICC simultaneously in the online learning community, where learners achieve shared learning objectives through computer-mediated communication.

\section{Synchronous components}

Synchronous online components such as a virtual class can provide learners with e-learning opportunities by enabling them to collaboratively interact with peers in a simulated regular classroom environment. Furthermore, multiple uses of recordings of synchronous components give learners the opportunity to study at their own pace until they are satisfied with their achievement. In the distance learning course discussed in this article, "Elluminate Live! (Elluminate, Inc. 2001-2010)," which is integrated into Blackboard, synchronous components were used to conduct a virtual class twice a week with the purposes of explaining new grammatical items, giving the students practice opportunities using the instructor's feedback in live sessions, and having question-and-answer sessions. Attendance at the virtual class was optional, but all sessions were recorded, so students who did not attend class because of a time conflict could watch it afterwards as many times as necessary. (Attendance at the virtual classes was optional, but students who attended each session received one extra credit point).

\section{Asynchronous components}

Attendance of virtual class was optional to accommodate a diverse group of students. To increase frequency of interaction so students could succeed in learning Japanese more effectively, asynchronous components were important elements of this distance learning course. In addition to the twice-weekly virtual class, instruction and assignments were delivered online on weekdays. Students completed paper workbook homework (which is regularly assigned in traditional face-to-face class sections) ${ }^{3}$ and were required to submit audio and video recordings that included grammar, vocabulary, and listening comprehension. For this course, an audio recording was assigned following a paragraphlength composition based on the topic of each lesson in the textbook, An Integrated Course in Elementary Japanese: Genki I, (Banno, Ohno, Sakane, \& Shinagawa, 1999); from these assignments, students were assessed mainly on their grammatical and vocabulary abilities. After grading the composition focusing on accuracy, the instructor made a sound file of the student's composition and returned the corrected composition and the sound file to the student. While listening to the sound file, the students practiced correct pronunciation and intonation based on what they wrote in their compositions before making a sound file and submitting it. The instructor then assessed the students' intonation and pronunciation as well as the accuracy of grammar and vocabulary.

Furthermore, students were assigned cultural activity projects involving three elements-instructor's scaffolding ${ }^{4}$, collaboration among peers, and learner autonomy - aimed at developing the abilities to analyze, integrate, and internalize the knowledge as well as language skills. Therefore, one purpose of a project included in the course schedule of each term was to compensate for the lack of interaction and negotiation of meaning as well as to maximize the students' individual skills and abilities in the distance learning setting. Although the tendency exists to give small segments of assignments or activities to students in basic-level language classes, each project was designed within the framework where the instructor's scaffolding embraces collaboration among peers and individual learner autonomy. The project in the first term provided students with opportunities to learn about the Japanese culture and the method of exchanging business cards. In the second term of this course, the students produced videos introducing their family members following the same process of the project of the first term although the number of steps was fewer. In the third term, the students were given two track options. The first option was to produce a comic, so the students could use a variety of speech styles and integrate their knowledge of grammar, vocabulary, and Japanese culture within the stories. The second option for students who did not want to make a comic required students to create a dialogue and videotape themselves acting out the dialogue, extending it to a skit.

\section{STUDENTS’ FEEDBACK FROM COURSE SURVEY}

Students' feedback regarding (a) benefits about the way in which this distance learning course was taught, (b) effective learning strategies they used and would like to share with their classmates, and (c) the most memorable moment in the course were examined. These items were selected to determine (a) characteristics of students taking Japanese in distance learning settings, (b) activities distance learning students feel are beneficial, and (c) strategies students developed in individual learning environments.

In terms of logistics of distance language education, the responses indicated that students in the distance learning class liked the flexibility of the schedule most as indicated by the following comments: "There is no mandatory class time-I have a family and full time job and am very busy!"; "It allows for flexibility in one's schedule"; and "The whole course is so flexible for students that can't attend classes physically. It is also good for students that like to learn on their own time and pace. It's awesome." Distance learning courses must provide flexible learning opportunities for diverse students who have busy schedules; therefore, they must allow students to learn at an individual pace. 
The students' responses regarding learning strategies and the most memorable moment in the distance learning class were analyzed and categorized into three different types of learning strategies based on White's (1995) study. White used metacognitive, cognitive, and socio-affective strategies because the scheme has a strong foundation in general learning theories in terms of the role of metacognition in learning, and the generic categories fit well with classroom and distance learning environments. Metacognitive strategies involve the awareness of learning processes and selfcontrolling abilities in the stages of planning, monitoring, and evaluating the learning activities. Compared with the metacognitive category, cognitive strategies are more directly related to individual learning tasks and involve the manipulation or transformation of the material to be learned. Socio-affective strategies influence social and affective processes of learning in the field of cognitive psychology. Social strategies involve interaction with others whereas affective strategies are concerned with the management skills of learners' own feelings about learning and language use. Table 1 shows the learning strategies revealed from the students' responses in the present distance learning courses.

TABLE 1.

LEARNING STRATEGIES USED BY DISTANCE LEARNING STUDENTS

\begin{tabular}{llc}
\hline Metacognitive strategies & Cognitive strategies & Socio-affective strategies \\
\hline - Monitoring listening & $\cdot$ Multiple-time access of & - Interaction with people from a \\
comprehension & recorded class session and & target language country \\
- Self-monitoring & materials & - Interaction with the instructor \\
- Increasing frequency of using a & - Simultaneous use of people & at virtual and office hours \\
target language class & from a target language country & - Sharing students' experience \\
- Study in shorter sessions as & and learning materials & online with their classmates \\
often as possible & $\cdot$ Making and using flashcards & - Involvement of family \\
& $\cdot$ Categorizing words on & members for study \\
& flashcards using different colors & \\
& $\cdot$ Exposure of a target language & \\
& $\cdot$ Memorization and rehearsing & \\
\hline
\end{tabular}

In O’Malley, Chamot, and Küpper's (1989) scheme of metacognitive strategies, learning is controlled through planning, monitoring, and evaluating the learning activity. Due to the nature of the beginning level of Japanese language courses, the structure of the course was organized by the instructor, and students were not given many opportunities to control the selection of their learning materials and activities. Consequently, responses describing the learning processes were not found; however, planning and monitoring occurred to promote learning in distance learning settings in the present investigation. Some students were aware of effective methods of learning, such as increasing frequency of using a target language such as "Studying frequently and note cards."; "I studied frequently in shorter sessions, which I think is important for learning any foreign language." Some students monitored conversations of native-speakers of Japanese and Japanese movies to develop listening comprehension abilities. : (e.g., "Beginning to understand my Japanese friends about halfway through the course!"; "Listening to people [who are] speaking Japanese."; "Listening skills can be improved by watching Japanese movies.") Self-monitoring was also found (e.g., "Record myself speaking and listening. And correcting.")

Many responses were collected regarding cognitive strategies that involve the manipulation or transformation of the materials to be learned. Some students reported that they benefitted from multiple opportunities to access recorded sessions of the virtual class because the virtual classes covered an appropriate amount of detail and offered ample practice as long as they watched it. Some significant responses included: "Being able to go over new material multiple times due to recorded sessions [is helpful]."; "Having the classes recorded made questions on the homework very easy to answer yourself."; and "The written audio homework assignments are the most helpful." Based on these responses, it can be assumed that the recording of each session and students' compositions describing personal or autobiographical topics or subjects related to the immediate environment helped students develop speaking skills more effectively than in the traditional face-to-face class, where students have only a one-time chance to listen in class. Furthermore, some students found that simultaneously using people from the target language country and learning materials is useful, as mentioned: "Online flash cards and full use of my roommate (he is here from Japan studying English)." It was also found that making and using flashcards (even classifying words in different colors) was an effective strategy to memorize and rehearse learning words and sentences for distance learning students, as indicated by the following comments: "...always having flash cards on hand,...trying each time to write it out, reading aloud"; "Making flashcards in different colors!" "Flashcards and memorization. You MUST be prepared to dedicate a lot of time if you plan to learn another language." Finally, it was pointed out that maximizing exposure of a target language is important. Some responses included: "Expose yourself to as much Japanese as possible." "Watching anime to help to reinforce what has been learned in the classroom," and "Practice using the language often in your home and in everyday situations."

Scio-affective strategies are methods to compensate the absence of classroom instruction for distance learning students. In the present investigation, several types of socio-affective strategies could help bridge the distance between students as well as the distance between the students and the instructor. Some students recognized that interaction with people from a target language country (e.g., "Recording the introduction video [with Japanese people] was the most memorable moment in this course."), and interaction with the instructor (e.g., "The final [oral exams]-the interaction is nice.") were helpful. It was pointed out that involvement of family members for study was also helpful (e.g., "My 
husband [and] I ...were able to practice with each other. This helped.”). In addition, events occurring in the virtual class and sharing the composition assignments posted on the Blackboard discussion board when conducting projects that involved collaboration were also listed (e.g., "I liked sharing my trip over winter break in one of the compositions.").

Thus, these findings could be interpreted that the online learning community support for distance learning students plays an important role in encouraging learning satisfaction, leading students to use appropriate learning strategies and enhancing instructional effectiveness.

\section{CONCLUSIONS AND Future PROSPECTS}

This article discussed how a first-year Japanese distance learning course was structured with consideration to provide instructor's scaffolding and collaboration among peers to accommodate a diverse group of students. The results from students' feedback from the course survey revealed a positive attitude toward learning environments in distance settings and learning similarly as students in face-to-face classes. It is challenging to teach a critical language in a distance learning class, but it is possible to bridge or minimize the distance separating student from student as well as student from instructor and to enhance students' success by effectively using asynchronous online components that emphasize social formation and a virtual class that synchronously combines support from the instructor and online learning communities.

Because the results of this investigation were obtained from beginning-level students, further studies are necessary to replicate and extend the study to involve students of different languages or levels. Furthermore, the means by which students developed autonomous learning abilities were not investigated during this nine-month period although students were asked to keep a written record of what they studied every day in a weekly study log when the author conducted a hybrid course prior to this study. Learning autonomy is required to succeed in distance learning courses; therefore, further research on the most effective ways to foster autonomous learning abilities for distance learning courses is needed.

\section{NOTES}

1. Although a final exam that evaluated students' achievement was conducted in each term, the standardized oral proficiency interviews were not included in the present distance learning course curricula.

2. The university where the author of this article teaches offers Japanese language courses for three terms in one year. Each term lasts ten weeks and has a total of 50 contact hours (five credit hours each term).

3. Although all other assignments, such as audio and video recordings as well as compositions were turned in using the assignment component of Blackboard for grading, paper workbook homework was self-graded using the model answers uploaded onto Blackboard. The instructor, however, encouraged students to submit the parts where students wrote their own answers (the parts where answers vary).

4. Scaffolding is first defined by describing young children's language acquisition and cognitive psychology. It represents helpful interactions between caretakers and children, enabling children to develop beyond the level where they are able to learn independently. It was applied to second language acquisition by Hatch (1978), and it refers to "the provision through conversation of linguistic structures that promote a learner's recognition or production of those structures or associated forms" (Chaudron, 1988).

5. The cooperative education (co-op) program provides students with multiple alternating work experiences whereby students can transfer learning between the classroom and workplace to prepare for further career paths. Therefore, some students with co-op assignments need to move from a face-to-face section to a distance learning section from term to term.

\section{APPENDIX 1. EXAMPLE OF PROMISING SYLlaBUS}

For distance-learning students in Basic Japanese Course

Learning a foreign language broadens a learner's perspectives, visions, and worldview. An American college student had a chance to participate in a short-term study abroad program to go to Japan in a group led by professors for a summer in her sophomore year. Although she had effectively learned Japanese in a classroom, communicating in Japan was difficult for her. The following summer, she decided to go back to Japan to completely immerse herself in the Japanese culture and language. She decided to go alone and live with her host family for two months in order to speak Japanese all the time and understand Japanese culture more deeply. As a result, she not only achieved a higher level of language proficiency, but she also developed insights of understanding cultural differences through interacting with students from all over the world in a language school.

During the first quarter of this course, you will be able to read and write phonetic alphabets such as Hiragana and Katakana. While learning the phonetic alphabets, you will also learn the sound system. Following mastering phonetic alphabets and the sound system, you will learn basic Japanese grammar and fifteen Kanji characters. Along with learning a new language, you will find and communicate cultural information regarding cultural differences. The ultimate goals of this course are to be able to express personal meaning, to participate in straightforward social situations, and to grasp a deeper cultural understanding. Although the students learn only 150 Kanji in the first-year 
Japanese course, there are thousands of characters in the Japanese language. Therefore, you will develop self-directed and life-long learning abilities as to search words and phrases you do not know.

\section{APPENDIX 2. EXAMPLE OF COURSE SURVEY}

This survey is anonymous. Your responses will help the instructor of the course to design future courses more effectively.

1. Please evaluate how frequently you used the following course resources.

\begin{tabular}{|l|l|l|l|l|}
\hline & Never & Infrequently & Frequently & Always \\
\hline Textbook & 0 & 1 & 2 & 3 \\
\hline Workbook & 0 & 1 & 2 & 3 \\
\hline Dictionaries & 0 & 1 & 2 & 3 \\
\hline Voc. Practice (PPT) & 0 & 1 & 2 & 3 \\
\hline Virtual Class Web & 0 & 1 & 2 & 3 \\
\hline $\begin{array}{l}\text { Blackboard } \\
\text { Activities }\end{array}$ & 1 & 2 & 3 \\
\hline Course Documents & 0 & 1 & 2 & 3 \\
\hline
\end{tabular}

2. Please evaluate how much you feel you have learned from the following course materials and class activities.

\begin{tabular}{|l|l|l|l|l|}
\hline & Nothing & $\frac{\text { Not very }}{\text { much }}$ & $\frac{\text { A Good }}{\text { Amount }}$ & $\underline{\text { A lot }}$ \\
\hline Composition & 0 & 1 & 2 & 3 \\
\hline $\begin{array}{l}\text { Audio- } \\
\text { Recording }\end{array}$ & 0 & 1 & 2 & 3 \\
\hline $\begin{array}{l}\text { Comics } \\
\text { Homework }\end{array}$ & 0 & 1 & 2 & 3 \\
\hline Textbook & 0 & 1 & 2 & 3 \\
\hline Workbook & 0 & 1 & 2 & 3 \\
\hline Dictionaries & 0 & 1 & 2 & 3 \\
\hline $\begin{array}{l}\text { Voc. Practice } \\
\text { (PPT) }\end{array}$ & 0 & 1 & 2 & 3 \\
\hline Virtual Class & 0 & 1 & 2 & 3 \\
\hline $\begin{array}{l}\text { Blackboard } \\
\text { Web Activities }\end{array}$ & 0 & 1 & 2 & 3 \\
\hline $\begin{array}{l}\text { Course } \\
\text { Documents }\end{array}$ & 0 & 1 & 2 & 3 \\
\hline $\begin{array}{l}\text { Discussion } \\
\text { Board }\end{array}$ & 0 & 1 & 2 & 3 \\
\hline
\end{tabular}

3. Please list the effective learning strategies you used and would like to share with your classmates.

4. Please write about the most memorable moment in this course.

5. Instructor grades homework and tests fairly.
Strongly agree
Agree
Somewhat agree No opinion

6. Instructor seems interested in the students and their progress.

Strongly agree Agree Somewhat agree No opinion

7. Instructor encourages use of Japanese.

Strongly agree Agree Somewhat agree No opinion

8. What is most beneficial aspect of the way this course is taught?

9. What suggestions would you make to improve this class?

10. Additional comments:

\section{REFERENCES}

[1] American Council on the Teaching of Foreign Languages (1999). ACTFL oral proficiency interview tester training manual. Yonkers, NY: ACTFL, Inc.

[2] Bain, K. (n.d.). The Promising Syllabus. Retrieved from http://www.bestteachersinstitute.org/promisingsyllabus.pdf.

[3] Banno, E., Ono, Y., Sakane, Y., \& Shinagawa, C. (1999). Genki I: An Integrated Course in Elementary Japanese. Tokyo: The Japan Times.

[4] Barners, D. (1976). From communication to curriculum. Harmondsworth: Penguin.

[5] Baron, N.S. (1984). Computer mediated communication as a force in language change. Visible Language. 18(2): 118-141.

[6] Baym, N.K. (1995). The emergence of community in computer-mediated communication. In S.G. Jones (Ed.), Cybersociety: Computer-mediated communication, and community (pp. 138-163). Thousand Oaks, CA: Sage Publications.

[7] Bonk, C.J. \& Cunningham, D.J. (1998). Searching for learner-centered, constructivist, and sociocultural components of collaborative educational learning tools. In C.J. Bonk \& K.S. King (Eds.), Instructional design: International perspectives.: Vol. 2. Solving Instructional Design Problems (pp. 369-397). Mahwah, NJ: Erlbaum. 
[8] Brown, K. M. (1996). The role of internal and external factors in the discontinuation of off-campus students. Distance Education, 17(1): 44-71.

[9] Bruner, J. (1966). Toward a theory of instruction. Cambridge, MA: Harvard University Press.

[10] Byram, M. (1997). Teaching and assessing intercultural communicative competence. Clevedon: Multilingual Matters.

[11] Byram, M. (2000). Assessing intercultural competence in language teaching. Sprogforum, 18(6): 8-13.

[12] Byram, M. \& Zarate, G. (1997). Definitions, Objectives and Assessment of Sociocultural Competence. In M. Byram, G. Zarate, \& G. Neuner (Eds.), Sociocultural competence in language learning and teaching. Strasbourg: Council of Europe.

[13] Chaudron, C. (1988). Second language classrooms. Cambridge: Cambridge University Press.

[14] Elluminate Inc. (2001-2010). Elluminate Live! [Software]. Available:http://www.elluminate.com/.

[15] Golladay, R., Prybutok, V. \& Huff, R. (2000). Critical success factors for the online learner. Journal of Computer Information Systems, 40(4): 69-71.

[16] Hara, N. \& Kling, R. (2000). Students' distress with a web-based distance education course: An ethnographic study of participants' experiences. Information, Communication and Society, 3(4): 557-579.

[17] Hatch, E.M. (1978). Second Language Learning-Universals? Working Papers on Bilingualism/Travaux de recherches sur le bilinguisme, 3: 1-17.

[18] Illich, I. (1979). Deschooling society. Harmondsworth: Penguin.

[19] Jonassen, D.H., Peck, K.L., \& Wilson, B.G. (1999). Learning with technology: A constructivist perspective. Upper Saddle River, NJ: Prentice Hall.

[20] Kiesler, S., Siegel, J., \& McGuire, T.W. (1984). Social psychological aspects of computer-mediated communication. American Psychologist, 39(10): 1123-1134.

[21] Kramsch, C. (1993). Context and culture in language teaching. Oxford: Oxford University Press.

[22] Liaw, M. (2006). E-learning and the development of intercultural competence. Language Learning \& Technology, 10(3): 49-64.

[23] Little, D. (1995). Learning as Dialogue: The dependence of learner autonomy on teacher autonomy. System, 23: 175-181.

[24] Lomicka, L. \& Lord, G. (2007). Social presence in virtual communities of foreign language (FL) teachers. System, 35: $208-228$.

[25] Michinov, N., Michinov, E., \& Toczek-Capelle, M.C. (2004). Social identity, group processes, and performance in synchronous computer-mediated communication. Group Dynamics: Theory, Research, and Practice, 8 (1): 27-39.

[26] National Standards in Foreign Language Education Project. (1999). Standards for foreign language learning in the $21^{\text {st }}$ century $\left(2^{\text {nd }}\right.$ ed.). Lawrence, KS: Allen Press.

[27] Nilson, L.B. (2007). The graphic syllabus and the outcomes map: Communicating your course. San Francisco, CA: JosseyBass.

[28] O’Malley, J.M., Chamot, A.U., \& Küpper, L. (1989). Listening comprehension strategies in second language acquisition. Applied Linguistics, 10 (4): 418-437.

[29] Rogers, C. (1983). Freedom to learn. New York: Merrill.

[30] Serwatka, J. (2003). Assessment in on-line CIS courses. Journal of Computer Information Systems, 43(3): 16-20.

[31] Stevenson, M.P. \& Liu, M. (2010). Learning a language with Web 2.0: exploring the use of social networking features of foreign language learning websites. CALICO Journal, 27(2): 233-259.

[32] U.S. Department of Education (2009). Evaluation of Evidence-Based Practices in Online Learning. Retrieved from http://www2.ed.gov/rschstat/eval/tech/evidence-based-practices/finalreport.pdf.

[33] White, C. (1995). Autonomy and strategy use in distance foreign language learning: Research findings. System, 23(2): $207-221$.

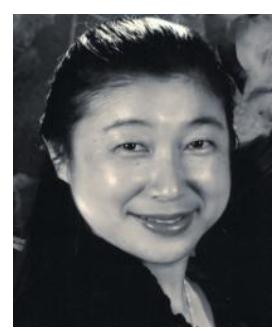

Noriko Fujioka-Ito was born in Japan. She earned Ph.D. and MA degrees majoring in foreign language education with Japanese linguistics and educational research minors from the Ohio State University, USA.

She teaches as an associate professor and coordinates Japanese courses at the University of Cincinnati, Ohio, USA. She has published in the journals such as Japanese Language Education around the Globe, Intercultural Communication Studies, Japan Studies Review, and Journal of Language Teaching and Research. Her research interests include learners' perceptions of error feedback, content-based instruction, distance learning education, and assessment of cultural proficiency.

Dr. Noriko Fujioka-Ito is a member of several academic organizations such as the American Association for Applied Linguistics, the American Association of Teachers of Japanese, the American Council on the Teaching of Foreign Languages, and the Japan Association for Language Teaching. 